\title{
Tracheotomy in ENT at CNHU HKM of Cotonou
}

\author{
Warou Dolou ${ }^{*}$, Stephen LA Lawson ${ }^{1}$, Sonia Lawson Afouda ${ }^{2}$, François Avakoudjo², \\ Wassi Adjibabi2 ${ }^{2}$ Berndadette Vignikin-Yehouessi ${ }^{2}$ \\ ${ }^{1}$ Department of Oto-Rhino-Laryngology, University Teaching Hospital of Kara, Kara, Togo \\ ${ }^{2}$ Department of Oto-Rhino-Laryngology, University Teaching Hospital Hubert Koutoukou MAGA (HKM), Cotonou, Benin \\ Email: *disamueli@live.fr
}

How to cite this paper: Dolou, W., Lawson, S.L., Afouda, S.L., Avakoudjo, F., Adjibabi, W. and Vignikin-Yehouessi, B. (2021) Tracheotomy in ENT at CNHU HKM of Cotonou. International Journal of Otolaryngology and Head \& Neck Surgery, 10, 526535.

https://doi.org/10.4236/ijohns.2021.106047

Received: October 18, 2021

Accepted: November 20, 2021

Published: November 23, 2021

Copyright (c) 2021 by author(s) and Scientific Research Publishing Inc. This work is licensed under the Creative Commons Attribution International License (CC BY 4.0).

http://creativecommons.org/licenses/by/4.0/

\begin{abstract}
Background: known since more than 5000 years, tracheotomy is indicated in severe obstructions of the upper airways or in improvement of ventilation in cases of problematic tracheal intubation. Its usefulness and efficiency are certain, but it needs regular assessments. Aim: to determine the frequency of tracheotomies in ENT at CNHU of Cotonou, identify the indications, surgical technics and the postoperative course. Materials and methods: the study was retrospective, based on files of patients who have had tracheotomies for ten years since 2010. Results: in 10 years, 105 tracheotomies were performed for 99 patients, average 10 to 11 per year. Patients were male in 61.9\%. Extreme of age where 09 months and 80 years old. Children under 15 were concerned in $41.9 \%$, while patients from 45 to 64 years old in 33.3\%. Emergency tracheotomy represented $76 \%$. Causes were tumors in $62.8 \%$. Laryngeal papillomatosis was the predominant tumor in children; 28 cases or $26.67 \%$. In adults, larynx cancer represented 20\%. Skin incisions were horizontal in $94.3 \%$. Tracheal opening was " $\mathrm{H}$-shaped" in $92.4 \%$. Complications occurred in $28.6 \%$. They included granuloma (13.3\%) and oeso-tracheal fistula (1.9\%). Decanulation was possible in $87.6 \%$, but it was more difficult in children. Conclusion: tracheotomy was an act of rescue in our practice.
\end{abstract}

\section{Keywords}

Tracheotomy, ENT Tumors, Emergency

\section{Introduction}

Tracheotomy is the temporary or permanent opening of the trachea followed by the placement of a cannula. It is an important procedure in the treatment or prevention of respiratory emergencies in ENT [1].

The procedure is known since a very long time: mentioned since $3600 \mathrm{BC}$ in 
ancient Egypt and described by Guy de CHAULIAC (1300-1368), a French monk; the surgical tracheotomy as currently known was codified by CHEVALIER JACKSON [2]. The progress of endoscopy and the increasing of indications in the intensive care unit have allowed the development of less invasive procedures not requiring a surgical opening: there came percutaneous techniques [3].

Challenges of tracheotomy depend on the conditions and situations of practice. Sub-Saharan Africa is associated with low socioeconomic populations, few ENT who are concentrated in the main urban areas, and limitations in terms of health facilities. These factors have implications such as:

- Late consultations of patients often seen in an emergency context in which tracheotomy is the first procedure performed, sometimes under difficult conditions.

- Increasingly frequent demand for tracheotomy, linked to the increase in indications and the creation of intensive care units whose equipment does not always follow.

- Limits for the specific management of the causal affection, tracheotomy being sometimes the only therapeutic gesture practiced.

Therefore it is useful to periodically review the practice of tracheotomy in ENT departments. Hence the present study makes an assessment of tracheotomy in an ENT department in Black Africa.

The aim of this study was to determine the incidence of tracheostomy in ENT at the National Teaching school of Medecine of Cotonou (CNHU HKM), and to identify the indications with the causal conditions, the techniques used and the results.

\section{Patients and Methods}

The study was retrospective and descriptive, made in the department of Otorhinolaryngology and Head and Neck Surgery of the CNHU of Cotonou in Benin. It concerned tracheotomies performed for ten years since 2011.

The inclusion criteria were:

- All tracheotomies performed in the CNHU HKM of Cotonou.

- Tracheotomy performed by a Physician (Resident or Senior) from the ENT department of the CNHU HKM of Cotonou.

- Complete surgical report specifying the types of skin and tracheal incisions, the type of cannula.

Exclusion criteria were incomplete files and patients lost to follow-up.

A pre-operative check-up was required for planned tracheotomies: frontal chest X-ray, blood-cell-count, blood type, prothrombin and cephalin time. No preoperative test was necessary for emergency cases.

Tracheotomies were performed in the ENT department operating room for patients planned for surgery or admitted during operating hours. On-call hours, tracheostomies were performed in the operating room of the emergency department. 
Patients admitted for upper obstructive dyspnea had a pre-medication including: corticosteroid therapy, prophylactic antibiotic therapy (amoxicillin + clavulanic acid or ceftriaxone) and pre-oxygenation. Corticosteroid therapy was administered at a dosage of 1 to $10 \mathrm{mg} / \mathrm{kg}$ in a bolus, renewable after 15 to 30 minutes. In case of persistent dyspnea, surgery was indicated. These parenteral treatments allowed the patient to be disinfiltrated, disinfected and oxygenated in order to perform the procedure in optimal conditions. In the postoperative period, patients were given analgesics and antibiotics (7 to 10 days, or more in case of other indications). Corticosteroid therapy was stopped between the third and fifth day. A chest X-ray was ordered in case of postoperative dyspnea.

Simple cannula care was performed daily by the nurses. Cannula changes were the responsibility of the physicians. Patients tracheotomized for prolonged intubation returned to the ICU immediately after the procedure. ENT staff were involved in their cannula care.

All patients had follow-ups noted in the records by ENT department physicians. Once the emergency was resolved, the etiology of the dyspnea was investigated with its appropriate treatment. For patients with a tumor, CT scan showed the lacoalisation an extension and histopathological examination specified the histopathological type.

Patients with normal breathing and unproblematic decanulation were considered cured. Patients who could not support decanulation or whose etiological treatment did not allow a favorable evolution were considered as failures.

The parameters studied were: the age, the gender, the context of the intervention: emergency or programmed, the indications, the involved pathologies involved, the type of anesthesia, the cutaneous and tracheal incisions, the types of cannulas, the specific postoperative courses of tracheotomy with the complications attributable to the procedure and the time before decanulation.

As some patients had tracheotomies several times, the study focused on the number of tracheotomies, the calculations concerned the parameters for each procedure and not the number of patients.

\section{Results}

During 10 years, 105 tracheotomies were performed in 99 patients. Four patients had it twice and one patient had three times.

Patients were male in 65 cases or $61.9 \%$ of tracheotomies. Sex ratio was 1.44 .

Age varied from 09 months to 80 years, with an average of 27.2 years. Children represented $41.9 \%$ against $58.1 \%$ for adults. Patient from 45 to 64 counted for $33.3 \%$ of tracheotomies. Table 1 summarizes the distribution of patients depending to age.

We reported 80 cases of emergency tracheotomy, performed for laryngeal dyspnea with vital prognosis, i.e. $76.2 \%$. Intubation tracheotomies concerned $16.2 \%$ and safety tracheotomies, were $7.6 \%$. In $62 \%$ cases, tracheotomies were indicated for tumors, followed by trauma in $18 \%$. Table 2 shows the distribution according to the etiologies and the type of tracheostomy. Figure 1 shows pictures 
Table 1. Distribution of cases by age group (in years).

\begin{tabular}{ccc}
\hline Age & $\mathrm{n}$ & $\%$ \\
\hline $00-05$ & 18 & 17.1 \\
$06-10$ & 19 & 18.1 \\
$11-15$ & 07 & 06.7 \\
$16-24$ & 06 & 05.7 \\
$25-34$ & 05 & 03.8 \\
$35-44$ & 05 & 04.8 \\
$45-54$ & 15 & 14.3 \\
$55-64$ & 19 & 19.0 \\
$65-75$ & 09 & 8.6 \\
$75-80$ & 02 & 1.9 \\
Total & 105 & 100 \\
\hline
\end{tabular}

Table 2. Distribution according to etiologies and types.

\begin{tabular}{|c|c|c|c|c|}
\hline Etiology & $\begin{array}{l}\text { Tracheotomy of } \\
\text { Intubation + safety }\end{array}$ & Emergency & Total & $\%$ \\
\hline Tumors & 17 & 48 & 65 & 62.8 \\
\hline Larynx & 08 & 42 & 50 & 47.6 \\
\hline Mandible & 04 & 01 & 05 & 04.8 \\
\hline Hypopharynx & 02 & 03 & 05 & 04.8 \\
\hline Cavum & 02 & 01 & 03 & 02.9 \\
\hline Oropharynx & 01 & 01 & 02 & 01.9 \\
\hline Traumatisms & - & 19 & 19 & 18.1 \\
\hline Larynx foreign bodies & - & 09 & 09 & 08.5 \\
\hline Face & - & 05 & 05 & 04.8 \\
\hline Laryngo-tracheal injury & - & 05 & 05 & 04.8 \\
\hline Infections/Inflammations & - & 12 & 12 & 10.5 \\
\hline Cervical cellulitis & - & 07 & 07 & 06.7 \\
\hline Laryngitis & - & 05 & 05 & 04.8 \\
\hline Prolonged ventilation & 06 & - & 06 & 05.7 \\
\hline Thyroid hypertrophy & 02 & - & 02 & 01.9 \\
\hline Laryngeal paralysis & - & 01 & 01 & 00.9 \\
\hline TOTAL & 25 & 80 & 105 & 100 \\
\hline
\end{tabular}

of cases where tracheotomy was performed.

In children, 44 tracheotomies were reported representing \% of total performed. Laryngeal papillomatosis was the first indication $(26.67 \%)$, followed by foreign bodies in upper respiratory tract $(8 \%)$, laryngitis $(4.8 \%)$, upper-glottic 


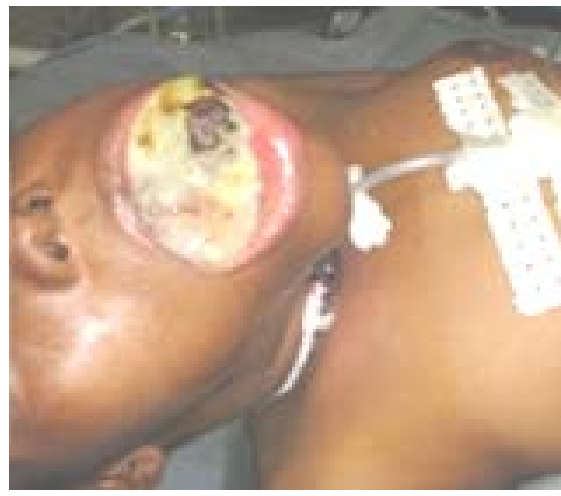

(a)
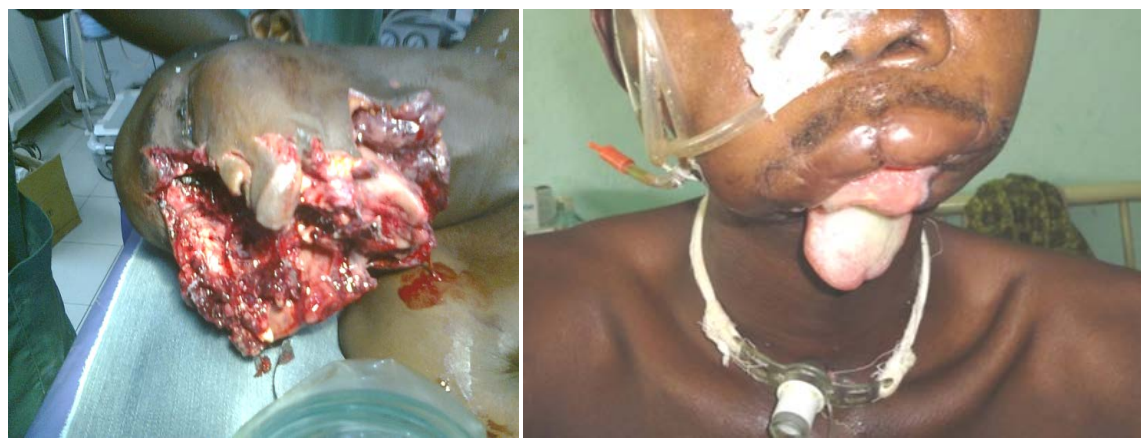

(c)

Figure 1. Iconography. (a) Tracheotomy of intubation performed for surgery for a large amelloblastoma; (b) 06 years-old male, tracheotomized twice for laryngeal papillomatosis; (c) Tracheotomy performed for a severe face injury caused by a gun.

angioma (0.95\%) and face obstructive tumor (0.95\%).

About the 65 tracheotomies in adults, $57.4 \%$ were indicated for tumors. These included 21 cases of laryngeal cancer, i.e. $20 \%$. These were patients with chronic dysphonia of the voice or woody type, followed by progressively worsening laryngeal dyspnea, which was a sign of laryngeal obstruction. Table 3 shows the distribution according to etiologies in adults.

Tracheostomy was performed under local anesthesia in 56.2\%. All tracheotomies were surgical. Table 4 details operative technique of the cases.

Postoperative course was uneventful in $71.4 \%$. Complications occurred in $28.6 \%$; $20.9 \%$ concerning emergency tracheotomies. Complications included: orificial granulomas (13.3\%), emphysema (4.8\%), infection (3.8\%), tracheal stenosis $(2.9 \%)$ and oeso-tracheal fistula (1.9\%). Two deaths (1.9\%) occurred during the anesthetic induction of tracheotomies indicated for prolonged intubation for a severe cerebral trauma and an encephalitis.

Decannulation was effective in $87.6 \%$, after an average duration of 18 days, extremes at 2 and 198. Table 5 shows the distribution according to the time to decanulation. Impossible decannulation was $4.8 \%$, including. It concerned a child tracheotomized since 09 years for laryngeal papillomatosis, and four adults respectively with laryngeal cancer, mandibular tumor, laryngeal malformation and laryngeal stenosis. 


\section{Discussion}

In terms of incidence: the study found an average of 10 to 11 tracheotomies per year. The same observation was made in 2007 by VIGNIKIN-YEHOUESSI B [4]

Table 3. Distribution of indications in adults.

\begin{tabular}{lcc}
\hline & $\mathrm{n}$ & $\%$ \\
\hline Malignant tumors & 32 & 52.5 \\
\multicolumn{1}{c}{ Larynx } & 21 & 20.0 \\
Hypopharynx & 5 & 4.8 \\
Cavum & 3 & 2.8 \\
Oropharynx & 2 & 1.9 \\
Mandibule & 1 & 0.9 \\
Benign tumors (pharynx and face) & 3 & 4.9 \\
Traumatisms & 10 & 16.4 \\
Extensive cervical cellulitis & 07 & 11.5 \\
Prolonged ventilation & 06 & 9.8 \\
Thyroid tumors & 02 & 3.3 \\
Laryngeal paralysis & 01 & 1.6 \\
\hline
\end{tabular}

Table 4. Distribution according to surgical technique.

\begin{tabular}{|c|c|c|}
\hline & Effectifs & $\%$ \\
\hline Anesthesia & 105 & 100 \\
\hline Local & 59 & 56.2 \\
\hline General & 46 & 43.8 \\
\hline Skin incision & 105 & 100 \\
\hline Horizontal & 99 & 94.3 \\
\hline Vertical & 6 & 5.7 \\
\hline Tracheal incision & 105 & 100 \\
\hline Under thyroid isthmus & 98 & 93.3 \\
\hline Sus-isthmic & 5 & 4.8 \\
\hline Trans-isthmic & 2 & 1.9 \\
\hline Shape of tracheal incision & 105 & 100 \\
\hline "I" or "H" & 97 & 92.4 \\
\hline “U” & 8 & 7.6 \\
\hline Cannula material & 105 & 100 \\
\hline Metallic & 65 & 61.9 \\
\hline Plastic & 40 & 38.1 \\
\hline Type of cannula & 105 & 100 \\
\hline Complete & 69 & 65.7 \\
\hline Incomplete & 36 & 34.3 \\
\hline
\end{tabular}


Table 5. Distribution according to time to decanulation.

\begin{tabular}{lcc}
\hline & $\mathrm{n}$ & $\%$ \\
\hline$<7$ days & 32 & 30.5 \\
7 to 30 days & 35 & 33.3 \\
$>30$ days & 25 & 23.8 \\
Death before decannulation & 08 & 07.6 \\
Impossible decannulation & 05 & 04.8 \\
Total & 105 & 100 \\
\hline
\end{tabular}

in the same department over a period of 15 years, as did DIOP EM [5] in Senegal, OUOBA K. [6] in Burkina and KPEMISSI E. [7] in Lomé, Togo. Higher incidence were reported in Europe, by PUCHER [8] in Poland and KOITSCHEV [9] in Germany with respectively 215 and 170 cases in 10 years. The increasing demand for tracheotomy in intensive care units (mainly percutaneous tracheotomies) in developed countries partly explains their higher incidence.

Regarding gender, a predominance of males (61.9\%) was noted in the ENT department at the Cotonou University Hospital. Same predominance was reported by KOFFI-AKA V [10] in Ivory Coast, YUEN H [11] and BABU V [12], with respectively found $78 \%, 74 \%$ and $70.2 \%$. It is explained by the predominance on adult males for obstructive pathologies of the upper aerodigestive tract such as laryngeal cancers ans cervical extensive cellulitis.

Concerning indications, emergency tracheotomies represented 76\% imposed by laryngeal dyspnea at stade III or IV. These situations need quick response to save life. This marked predominance of rescue tracheotomies can be explained by the late consultations linked to poverty or to the long health paths of patients before arriving in a specialized environment. This is common in developing countries, of which Benin is a part, such as Burkina Faso [6], Ivory Coast [10] or Senegal [5]. In developed countries, emmergency tracheotomies are performed in lower proportions, as reported by YUEN H [11] in Singapore with $49 \%$ or CHARFEDDINE [22] in Tunisia with $48 \%$.

In adults, it was mostly laryngeal cancer representing $20 \%$ of the cases. This finding is confirmed by other authors such as KOFFI-AKA V [10], BABU V [12] and YUEN H [11] with respectively $31.5 \% 22.8 \%$ and $18.5 \%$.

In children, laryngeal papillomatosis was the first indication. This benign tumor is fatal because of its laryngeal site [13] which is fragile and high in the child. Symptoms are early dysphonia, followed by dyspnea at rest, evolving to a real asphyxia. The evolution is unpredictable, with frequent recurrences, especially in the florid forms. Tracheotomy is not recommended because it would favor the tracheal diffusion of papillomatosis [13]. However, in the study series, $26.67 \%$ of tracheostomies were due to laryngeal papillomatosis because the children were admitted with respiratory distress. In this context and given the difficulties of intubation because of the characteristics of the child's larynx (very 
spasmogenic), in addition to the risk of diffusion of the clusters to the trachea, rescue tracheotomy is necessary in order to save the life immediately. The results of the series are comparable to those of VODOUHE SJ [14] with 20.3\% (p < 0.001) and significantly lower than that of KOFFI AKA V [10] who reported $37.9 \%$. Laryngeal papillomatosis represented $63.6 \%$ of the indications for pediatric tracheotomies in the study series. In this indication, trachotomy is often an emergency procedure as reported by DIOP [15] in Senegal and FASUNLA I [16] in Nigeria respectively $50.8 \%$ and $90 \%$.

Other indications were encountered: dyspneic acute laryngitis represented $4.76 \%$ of the indications, a value close to that of. VIGNIKIN-YEHOUESSI in 2007 [4] with 3.53\% but different from the results of BABU V [12] B and YUEN $\mathrm{H}$ [11] with respectively $1.90 \%$ and $8.2 \%$. Trauma represented $18.1 \%$ of the indications for tracheotomy, including $8.57 \%$ for laryngotracheal foreign bodies. This result was close to the $8.22 \%$ reported by VIGNIKIN-YEHOUESSI B [4]. AMUSA YB [17] recorded a higher proportion with $13.6 \%$ of laryngotracheal trauma. Cervicofacial cellulitis represented $6.7 \%$ of indications, close to the $7.8 \%$ recorded by LAWSON AFOUDA [18]. Prolonged intubation represented 5.7\% of the indications. In these cases, tracheostomy allows the prevention of laryngeal lesions secondary to prolonged intubation, to secure the tracheal approach especially in agitated patients, to improve patient comfort and to facilitate nursing care [19] [20] [21].

Local anaesthesia was predominant with $61.9 \%$ of the reported cases. This result was confirmed by BABU V with 58\% [12], CHARFFEDINE with 64\% [22] and AMUSA YB with 68\% [17]. It can be explained by the difficulties in achieving effective intubation in patients who arrive at stages of dyspnoea that do not allow general anaesthesia under the best conditions. Local anaesthesia is less convenient than general anaesthesia, because it needs the procedure to be quick and efficient to avoid respiratory decompensation. However, when the emergency situation requires trachetomy to be performed as quickly as possible to save the patient, local anaesthesia is be best choice.

All the tracheotomies of the series were performed according to the classical surgical technique, because of the lack of material for the transcutaneous tracheotomies which require moreover an endoscopic control. This was the case for the series by VODOUHE [14] and AMUSA YB [17]. This place of classical tracheotomy by cervicotomy does not necessarily reflect a gap in the practices of the Cotonou department in relation to technical advances, because and YUEN H [11] and BABU V [12] reported the same result with better equipments.

Horizontal cutaneous incisions are still the most common: $94.3 \%$ in the study series, $100 \%$ in BABU V [12]. In the study series as well as in other series [10] [11] [12] [22], the tracheal incisions were " $H$ " or " $U$ " shaped. The sub-isthmic site was the majority in the study series with $88 \%$ of cases, similar to the results of YUEN H [8], 89.2 with $84 \%$ and AMUSA YB [17] with 90\%. Sub-isthmic tracheostomies allow a shorter, less hemorrhagic and more convenient procedure. 
In the study series, the cannulas used were metallic in $65 \%$ of cases. They offer the advantage of being easily recyclable. KOFFI-AKA V [10] also reported a predominance of silver metal cannulas, the only variety available in their department.

About the postoperative course: complications represented $28.6 \%$ of the cases. Lower rates were recorded by BABU V [12] with 9.5\% and YUEN H [11] 8.2\%, who had a better technical platform and working conditions. Complications also depend on the quality of the cannular care. In the study series, decanulation was possible in $87.6 \%$. Variable rates are reported by several authors, ranging from $75 \%$ to $92 \%$ [11] [12] [16]. Removal of a tracheostomy cannula depends on the disappearance of the causative condition. Removal of a tracheostomy tube depends on the disappearance of the causative condition. Difficulties with decanulation in children are related to laryngeal papillomatosis, a condition with an unpredictable course and possible recurrence.

\section{Conclusion}

Tracheostomy is a therapeutic procedure of survival whose usefulness and effectiveness are certain. It is necessary to know how to perform it cold in order to save human lives, especially children. Let us keep in mind that it is sometimes associated with complications that can be fatal in some cases.

\section{Disclosure of Interest}

No disclosure related to this publication.

\section{Conflicts of Interest}

The authors declare no conflicts of interest regarding the publication of this paper.

\section{References}

[1] Laccourreye, L. and Dubin, J. (2001) Trachéotomie. Encyclopédie Médico-Chirurgicale (Editions Scientifiques et Médicales SAS, Paris, tous droits réservés), Techniques chirurgicales-tête et cou, 46-430.

[2] Chevalier, J. (1909) Tracheostomy. The Laryngoscope, 19, 285-290. https://doi.org/10.1288/00005537-190904000-00003

[3] Willemot, J. (1983) Naissance et développement de l'oto-rhino-laryngologie dans l'histoire de la médecine. Acta Oto-Rhino-Laryngoligica Belgica, 35, 81-90.

[4] Vignikin-Yehouessi, B., Flatin, M., Hounkpe, P.C.L., et al. (2007) Place of Tracheotomy in ENT Practice at the CNHU of Cotonou. Revue Africained'Anesthésie et d'Urgences, 12, 79-89.

[5] Diop, E.M., Tall, A., Diouf, R., et al. (2007) Management of Laryngeal Foreign Bodies in Children in Senegal. Archives de Pédiatrie, 7, 10-15.

https://doi.org/10.1016/S0929-693X(00)88911-3

[6] Ouoba, K., Onadja, N., Dao, O.M., et al. (2004) Place of Tracheotomy at the University Hospital of Ouagadougou in Burkina-Faso. Revue Africaine d ORL et CCF, 2, 104-111. 
[7] Kpemissi, E., Sossou, K., Medji, L.A., et al. (1996) Tracheostomy: Assessment of 5 Years at the University Hospital of Lomé. Revue des Maladies Respiratoires, 13, 163-167.

[8] Pucher, B., Szydlowski, J., Steiner, I., et al. (2006) Tracheotomy in Children of the Pediatric ENT Department in Years 1995-2005. Otolaryngologia Polska, 60, 525528.

[9] Koitschev, A., Simon, C., Blumenstock, G., et al. (2006) Surgical Technique Affects the Risk for Tracheostoma-Related Complication in Post-ICU Patients. Acta OtoLaryngologica, 126, 1303-1308. https://doi.org/10.1080/00016480600702134

[10] Koffi-Aka, V., Kouassi, A., Adjoua, R., Meideros, E., et al. (2004) Emergency Tracheotomy: Experience of the ENT Department of the CHU of Treichville (Abidjan). Médecine d' Afrique Noire, 51, 301-304.

[11] Yuen, H.W., Heng-Chian, A.L. and Johari, S. (2007) Urgent Awake Tracheotomy for Impending Airway Obstruction. Otolaryngology-Head and Neck Surgery Singapore, 136, 838-842. https://doi.org/10.1016/j.otohns.2006.12.012

[12] Babu, V., Mohiyuddin, S., Narasimhan, I., Venkatesh, N. and Nair, P. (2010) Emergency Tracheotomy-A Six Year Experience of a Rural Tertiary Hospital. The Internet Journal of Otorhinolaryngology, 12,178-181.

[13] Conessa, C., Hervé, S., Roguet, E., Gauthier, J. and Poncet, J.L. (2005) Surgery of Benign Tumors of the Larynx. EMC-Chirurgie, 2, 709-724. https://doi.org/10.1016/j.emcchi.2005.10.004

[14] Vodouhe, S.J., Beda, K.A.J., Hounkpe, Y.Y.C. and Medji, A.P.L. (1996) Tracheostomy in an ENT and Cervicofacial Surgery Department at the C.N.H.U of Cotonou. Bénin Médical, 5, 167-170.

[15] Diop, E.M., Ndiaye, I., Tall, A., et al. (2008) Laryngeal Papillomatosis in Children. Oto-Rhino-Laryngologie, 94, 379-382.

[16] Fasunla, A.J. and Lasisi, O.A. (2009) Diagnostic Challenges of Laryngeal Papillomatosis and Its Implications among Children in Developing Country. International Journal of Pediatric Otorhinolaryngology, 73, 593-595. https://doi.org/10.1016/j.ijporl.2008.12.009

[17] Amusa, Y.B., Akinpelu, V.O., Fadiora, S.O. and Agbakwuru, E.A. (2004) Tracheostomy in Surgical Practice: Experience in a Nigerian Tertiary Hospital. West African Journal of Medicine, 23, 256-259. https://doi.org/10.4314/wajm.v23i1.28077

[18] Lawson Afouda, S., Avakoudjo, F., Alamou, S., Hounkpatin, S.H.R., Satowakou, M., Hounkpe, Y.Y.C. and Adjibabi, W. (2012) Etio-Epidemiological and Therapeutic aspects of Cervico-Facial Cellulitis of Dental Origin. Revue de Laryngologie Otologie Rhinologie, 133, 197-200.

[19] Jalisi, S. and Zoccoli, M. (2010) Management of Laryngeal Fractures 10 Year Experience. Department of Otolaryngology-Head and Neck Surgery, Boston University Medical Center. Journal of Voice, 1, 733-735.

[20] Aissaoui, Y., Azendour, H., Balkhi, H., Haimeur, C., et al. (2007) Time to Tracheostomy and Outcome of Mechanically Ventilated Patients. Annales Françaises d Anesthésie et de Réanimation, 26, 496-501.

[21] Epstein, S.K. (2005) Late Complications of Tracheostomy. Respiratory Care, 50, 231233.

[22] Charfeddine, I., Hammami, B., Bouayed, W., Chakroun, A. and Ghorbel, A. (2008) Total Laryngectomy, the Experience of the ENT Department of Sfax. Journal Tunisien d ORL, 20, 159-161. 